\title{
Laboratory performance of stone matrix asphalt mixtures with two aggregate gradations
}

\author{
Goutham Sarang • B. M. Lekha $\cdot$ J. S. Geethu • \\ A. U. Ravi Shankar
}

Received: 24 October 2014/Revised: 17 March 2015/Accepted: 19 March 2015/Published online: 8 April 2015

(C) The Author(s) 2015. This article is published with open access at Springerlink.com

\begin{abstract}
Stone matrix asphalt (SMA) is a gap-graded bituminous mixture which can be used in surface layer of high volume pavements. The mixture has higher concentrations of coarse aggregates, providing strength and rut resistance to the mixture, and higher asphalt content giving durability. There must be a proper stone-to-stone contact between the coarse aggregates of SMA, and hence aggregate gradation is an important factor in this mixture. In the current study, two aggregate gradations, with nominal maximum aggregate sizes (NMAS) 16 and $13 \mathrm{~mm}$ were adopted to prepare SMA mixtures and their laboratory performances were compared. Polymer-modified bitumen (PMB) was used as the binder material and no stabilising additive was used, since drain down was within permissible limits for both mixtures with PMB. Conventional cylindrical specimens were prepared in superpave gyratory compactor with bitumen contents $5.0 \%, 5.5 \%, 6.0 \%$, $6.5 \%$ and $7.0 \%$ by weight of aggregates, and volumetric and Marshall properties were determined. Tensile strength, behaviour to repeated loading etc. were checked for cylindrical specimens prepared at optimum bitumen content, whereas specially prepared slab specimens were used to check the rutting resistance of SMA mixtures. From the laboratory study, it was observed that, out of the two SMA mixtures, the one with NMAS $16 \mathrm{~mm}$ performed better compared to the other. These improved properties may be
\end{abstract}

Electronic supplementary material The online version of this article (doi:10.1007/s40534-015-0071-5) contains supplementary material, which is available to authorized users.

G. Sarang $(\bowtie) \cdot$ B. M. Lekha · J. S. Geethu · A. U. R. Shankar Department of Civil Engineering, National Institute of Technology Karnataka, Surathkal, Srinivasnagar PO,

Mangalore 575025, Karnataka, India

e-mail: gouthamsarang@gmail.com attributed towards the larger coarse aggregate sizes in the mixture.

Keywords Stone matrix asphalt - Stone-to-stone contact . Drain down · Aggregate gradation - Nominal maximum aggregate size

\section{Introduction}

Stone matrix asphalt (SMA) is a gap-graded HMA developed in Germany in the 1960's, to resist the wear and tear on pavements caused by studded tyres. Later the mix was found to be more rut resistant and durable than conventional dense-graded mixtures and this encouraged other European countries also to utilise this mixture [1]. Some transportation agencies from USA conducted a study tour to Europe in 1990 and they were impressed with the performance of SMA [2]. This led to detailed laboratory and field investigations on SMA and its successful performance made the mixture one of the primary choices for pavement engineers.

Stone matrix asphalt has higher proportion of coarse aggregates and binder mortar compared to conventional mixtures. Good stone-to-stone contact exists between the aggregates forming coarse aggregate skeleton, which provides better strength and rut resistance to the mixture. The coarse aggregate skeleton contributes to the shear strength and effective loading distribution pattern of vehicles to endure heavier traffic loads compared to the dense-graded mixtures [3-5]. The rich binder mortar consisting of fine aggregates, bituminous binder, mineral filler and generally a stabilising additive also provides durability to the mixture due to higher binder and filler content. Stabilising additive is used to control drain down, which is a usual phenomenon 
in gap-graded mixtures with higher bitumen and filler content like SMA, where a portion of bitumen and fines may be separated and flow down from the mixture during the elevated temperatures of production, transport, laying and compaction.

\subsection{Aggregate gradation}

Many researchers have observed that the gradation of aggregates is having a significant effect on the performance of different types of HMA's [6-9]. Brown and Bassett [6] studied the effects of maximum aggregate size (MAS) on the properties of asphalt aggregate mixtures by conducting studies on five different aggregate gradations with five MAS's. Xie et al. [10] and Cooley and Hurley [11] studied the performance of SMA mixtures with different nominal maximum aggregate sizes (NMAS) $(9.5$ and $4.75 \mathrm{~mm}$ ). The basic principle of SMA lies on the coarse aggregate skeleton, and it is very important to achieve proper stoneto-stone contact with good quality aggregates for any SMA mixture. Coarse aggregates with Los Angeles abrasion value $<30 \%$ were observed to give better performance to SMA [12]. Inferior quality aggregates may lead to aggregate break down during mixing and compaction, which could alter the mix gradation, potentially causing a loss of stone-on-stone contact between the coarse aggregate particles [13].

Generally, SMA has about $70 \%$ coarse aggregates and comparatively higher filler and bitumen content. There is a 30-20-10 thumb rule, traditionally followed by many agencies for SMA gradation. As per this rule, SMA mixture should have $30 \%, 20 \%$ and $10 \%$ materials passing through standard sieves $4.75,2.36 \mathrm{~mm}$ and $75 \mu$, respectively [14]. Different countries and agencies developed aggregate gradations for SMA mixture. To check the stoneto-stone contact between coarse aggregates, determination of voids in coarse aggregates (VCA) method was suggested by Brown and Mallick [15]. VCA for aggregates in dryrodded condition $\left(\mathrm{VCA}_{\mathrm{DRC}}\right)$ and also for the entire mixture $\left(\mathrm{VCA}_{\mathrm{MIX}}\right)$ were calculated using Eqs. 1 and 2, and for stone-to-stone contact to exist, $\mathrm{VCA}_{\mathrm{MIX}}$ should be less than $\mathrm{VCA}_{\mathrm{DRC}}$.

$\mathrm{VCA}_{\mathrm{DRC}}=\frac{\left(G_{\mathrm{CA}} Y_{\mathrm{W}}-Y_{\mathrm{S}}\right)}{G_{\mathrm{CA}} Y_{\mathrm{W}}} \times 100$,

$\mathrm{VCA}_{\mathrm{MIX}}=100-\left(\frac{G_{\mathrm{MB}}}{G_{\mathrm{CA}}} \times P_{\mathrm{CA}}\right)$,

where $G_{\mathrm{CA}}$ is the bulk specific gravity of the coarse aggregate fraction, $Y_{\mathrm{W}}$ is the unit weight of water $\left(998 \mathrm{~kg} / \mathrm{m}^{3}\right), Y_{\mathrm{S}}$ is the unit weight of coarse aggregate fraction in dry-rodded condition $\left(\mathrm{kg} / \mathrm{m}^{3}\right)$ (determined in accordance with ASTM C 29), $G_{\mathrm{MB}}$ is the Bulk specific gravity of compacted mixture, $P_{\mathrm{CA}}$ is the Percent coarse aggregate in the total mixture.

In India, based on the guidelines provided by Kandhal [16], Indian Roads Congress (IRC) has issued a special publication for SMA [17] in 2008, but the implementation of this mixture in field is very limited. Compared to other bituminous mixtures, aggregate gradation is more significant in the case of SMA mixtures. The main objective of this investigation is to prepare SMA mixtures with two different aggregate gradations and compare them based on their performance in various laboratory tests. Two different aggregate gradations with two NMAS were adopted for SMA and mixtures were prepared to satisfy the requirements as per IRC. The type and source of aggregates, bituminous binder and all other constituent materials were same so that the difference between mixtures is only due to the aggregate gradation and NMAS.

\section{Materials used}

Crushed granite aggregates collected from nearby quarry were used to prepare SMA mixtures. The aggregates were having good quality and satisfied the necessary requirements for SMA. The physical properties of aggregates were tested and are presented in Table 1. Generally, a modified bituminous binder is suitable in SMA to control drain down, or else suitable stabilising additive should be used. Polymer-modified bitumen (PMB) manufactured with polymer (elastomeric or plastomeric) as the modifier under carefully controlled conditions, results in enhanced properties and this makes it suitable for wearing course application under high traffic and rainfall [18]. PMB grade 70 is recommended by IRC for atmospheric temperature of $35-45{ }^{\circ} \mathrm{C}$, and the same was used in this investigation. Basic properties of PMB were tested and are reported in Table 2. Quarry dust and hydrated lime were used as mineral filler, and quantity of lime was limited to $2 \%$ by weight of aggregates.

In this study, two different aggregate gradations with NMAS 16 and $13.2 \mathrm{~mm}$ were considered to prepare SMA mixtures and they are named as SMA 1 and SMA 2, respectively. Gradation for SMA with $16 \mathrm{~mm}$ NMAS (SMA 1) was adopted from Chinese specifications [19] and that with 13.2 mm NMAS (SMA 2) from IRC [17] and are presented in Table 3. The SMA mixture requirements as per IRC are presented in Table 4.

\section{Experimental investigation}

SMA mixtures with both aggregate gradations were prepared with bitumen contents $5.0 \%, 5.5 \%, 6.0 \%, 6.5 \%$ 
Table 1 Properties of coarse aggregates

\begin{tabular}{lll}
\hline Property & Results & $\begin{array}{l}\text { IRC SP 79 } \\
\text { requirements }\end{array}$ \\
\hline Aggregate impact value & $15.89 \%$ & $24 \%$ maximum \\
Los Angeles abrasion value & $16.40 \%$ & $25 \%$ maximum \\
Water absorption & $0.35 \%$ & $2 \%$ maximum \\
Specific gravity test & 2.64 & - \\
$\begin{array}{l}\text { Combined flakiness and elongation } \\
\text { index }\end{array}$ & $23.5 \%$ & $30 \%$ maximum \\
\hline
\end{tabular}

Table 2 Properties of PMB

\begin{tabular}{ll}
\hline Property & $\begin{array}{l}\text { Results } \\
\text { obtained }\end{array}$ \\
\hline $\begin{array}{l}\text { Penetration }\left(100 \text { gramme, } 5 \text { s at } 25{ }^{\circ} \mathrm{C}\right)(1 / 10 \text { th of } \\
\text { mm) }\end{array}$ & 60.4 \\
$\begin{array}{l}\text { Softening point, }{ }^{\circ} \mathrm{C}(\text { Ring \& Ball Apparatus) } \\
\text { Ductility at } 27{ }^{\circ} \mathrm{C}(5 \mathrm{~cm} / \mathrm{min} \text { pull) }(\mathrm{cm})\end{array}$ & 59 \\
Flash point $\left({ }^{\circ} \mathrm{C}\right)$ & $>100$ \\
Viscosity at $150{ }^{\circ} \mathrm{C}$, poise & 244 \\
Test on residue for thin film oven tests & 3.5 \\
Loss in mass $(\%)$ & 0.088 \\
Increase in softening point $\left({ }^{\circ} \mathrm{C}\right)$ & 4 \\
Reduction in penetration of residue $\left(\right.$ at $\left.25{ }^{\circ} \mathrm{C} \%\right)$ & 22.5 \\
Elastic recovery of half thread in ductilometer at & 65 \\
$25{ }^{\circ} \mathrm{C}(\%)$ & \\
\hline
\end{tabular}

and $7.0 \%$ by weight of aggregates. Specimens were compacted in superpave gyratory compactor (SGC) by giving 100 gyrations and maintaining the ram pressure, gyration angle and rate of gyration as $600 \mathrm{kPa}, 1.25^{\circ}$ and $30 \mathrm{rpm}$ respectively. For all tests other than rutting test, minimum three specimens were prepared for each SMA mixture and the average of the three values was considered, whereas two SMA slabs were prepared for each mixture to evaluate rutting.

\subsection{Drain down}

Drain down test was conducted as per ASTM D 6390 in a wire basket made up of standard sieve cloth of $6.3 \mathrm{~mm}$ size (shown in Fig. 1), at temperatures 160 and $170{ }^{\circ} \mathrm{C}$. A known weight of SMA mixture is prepared and poured in the basket and is hung in an oven maintained at test temperature. The material drained during the test period of $1 \mathrm{~h}$ is collected in a catch plate and weighed. The ratio of weight of material drained to the initial weight of mixture is known as drain down. In this study, drain down was observed to be $<0.3 \%$, the specified maximum limit, for both SMA 1 and SMA 2.
Table 3 Aggregate Gradation for SMA

\begin{tabular}{|c|c|c|c|c|}
\hline \multirow[t]{3}{*}{ IS sieve size $(\mathrm{mm})$} & \multicolumn{4}{|c|}{$\begin{array}{l}\text { Cumulative } \% \text { by weight of total aggregate } \\
\text { passing }\end{array}$} \\
\hline & \multicolumn{2}{|c|}{$\begin{array}{l}\text { SMA } 1 \text { (NMAS } \\
16 \mathrm{~mm})\end{array}$} & \multicolumn{2}{|c|}{$\begin{array}{l}\text { SMA } 2 \text { (NMAS } \\
13 \mathrm{~mm} \text { ) }\end{array}$} \\
\hline & Range & Adopted & Range & Adopted \\
\hline 19 & 100 & 100 & 100 & 100 \\
\hline 16 & $90-100$ & 95 & - & - \\
\hline 13.2 & $60-80$ & 70 & $90-100$ & 95 \\
\hline 9.5 & $40-60$ & 50 & $50-75$ & 62.5 \\
\hline 4.75 & $20-32$ & 26 & $20-28$ & 24 \\
\hline 2.36 & $18-27$ & 22 & $16-24$ & 20 \\
\hline 1.18 & $14-22$ & 18 & $13-21$ & 18 \\
\hline 0.6 & $12-19$ & 16 & $12-18$ & 16 \\
\hline 0.3 & $10-16$ & 14 & $10-20$ & 14 \\
\hline 0.15 & 9-14 & 12 & - & - \\
\hline 0.075 & $8-12$ & 10 & $8-12$ & 10 \\
\hline
\end{tabular}

Table 4 SMA mixture requirements

\begin{tabular}{ll}
\hline Mix design parameters & Requirements \\
\hline Air void content $(\%)$ & 4.0 \\
Bitumen content $(\%)$ & 5.8 minimum \\
Voids in mineral aggregates & 17 minimum \\
(VMA) (\%) & \\
Voids in coarse aggregates mix & Less than VCA in the dry-rodded \\
(VCA $_{\text {MIX }}(\%)$ & condition $\left(\mathrm{VCA}_{\mathrm{DRC}}\right)$ \\
Asphalt drain down (\%) & 0.3 maximum \\
Tensile strength ratio (TSR) & 80 minimum \\
$(\%)$ & \\
\hline
\end{tabular}

\subsection{Volumetric and Marshall properties}

Maximum theoretical specific gravity $\left(G_{\mathrm{MM}}\right)$ was determined for each mixture in loose uncompacted form using asphalt density tester, as per ASTM D 2041. Cylindrical SMA specimens were prepared in SGC and their dimensions and weights were measured to calculate the volumetric properties like bulk specific gravity $\left(G_{\mathrm{MB}}\right)$, air voids $\left(V_{\mathrm{A}}\right)$, voids in mineral aggregates (VMA) and voids filled with bitumen (VFB). $G_{\mathrm{MM}}$ was observed to be between $2.43-2.50$ and $2.41-2.49 \mathrm{~g} / \mathrm{cm}^{3}$ for SMA 1 and SMA 2 mixtures respectively, and $G_{\mathrm{MB}}$ between $2.34-2.37$ and $2.33-2.35 \mathrm{~g} / \mathrm{cm}^{3}$. VMA was above $17 \%$ for both mixtures and $\mathrm{V}_{\mathrm{A}}$ was in the range $3.0 \%-6.6 \%$. Marshall test was conducted as per ASTM D 6927 to determine the stability and flow of each specimen. Marshall stability was observed between 14.6-20.1 and 14.5-19.4 kN, respectively, for SMA 1 and SMA 2 mixtures. SMA 1 mixtures have comparatively better properties than SMA 2, including $G_{\mathrm{MM}}, G_{\mathrm{MB}}$, Marshall stability etc. $\mathrm{VCA}_{\mathrm{DRC}}$ depends only 


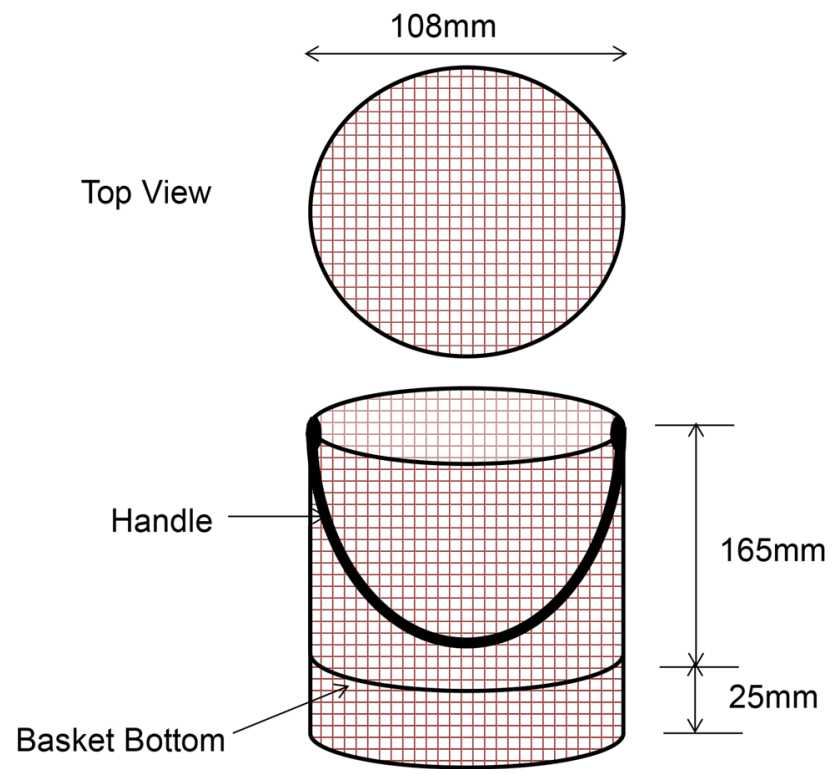

Fig. 1 Wire basket assembly for drain down test

on the aggregate properties and gradation, and was obtained as $42.68 \%$ and $43.47 \%$ for SMA 1 and SMA 2, respectively. For all mixtures of SMA 1 and SMA 2, $\mathrm{VCA}_{\mathrm{MIX}}$ values were less than the corresponding $\mathrm{VCA}_{\mathrm{DRC}}$ values, and this ensured stone-to-stone contact between the coarse aggregates. Volumetric characteristics and Marshall properties of both SMA mixtures at bitumen contents $5 \%-7 \%$ are presented in Table 5.

Mixtures of both gradations with all bitumen contents satisfied the SMA mixture requirements and hence only air voids were considered as the determining factor for optimum bitumen content (OBC), and bitumen content corresponding to $4 \%$ air voids is taken as the OBC. For SMA 1 , it was $6.00 \%$, whereas for SMA 2 it was slightly higher
Table 6 Volumetric and Marshall properties at OBC

\begin{tabular}{lcc}
\hline Property & Mixture & \\
\cline { 2 - 3 } & SMA 1 & SMA 2 \\
\hline OBC $(\%)$ & 6.00 & 6.12 \\
$G_{\mathrm{MM}}\left(\mathrm{g} / \mathrm{cm}^{3}\right)$ & 2.463 & 2.445 \\
$G_{\mathrm{MB}}\left(\mathrm{g} / \mathrm{cm}^{3}\right)$ & 2.366 & 2.347 \\
VMA $(\%)$ & 17.33 & 18.86 \\
VFB $(\%)$ & 75.72 & 78.73 \\
MS $(\mathrm{kN})$ & 19.60 & 19.13 \\
FV $(\mathrm{mm})$ & 3.99 & 3.52 \\
MQ $\left(\mathrm{kN} / \mathrm{mm}^{2}\right)$ & 4.91 & 5.43 \\
VCA $_{\mathrm{MIX}}$ & 39.37 & 38.52 \\
VCA $_{\mathrm{MIX}} / \mathrm{VCA}_{\text {DRC }}$ & 0.922 & 0.886 \\
\hline
\end{tabular}

$(6.12 \%)$. The increased density of SMA 1 caused less air voids and this provided less OBC value. The volumetric and Marshall properties of both mixtures at corresponding OBC are presented in Table 6.

\subsection{Indirect tensile strength (ITS)}

Indirect tensile strength is a measure of tensile strength of bituminous mixtures measured along the diametral plane of cylindrical specimens, as per AASHTO T 283 specification. In this method, specimens are tested in normal conditions and also after subjecting to accelerated weathering phenomenon. Accelerated weathering is induced in laboratory by conditioning the specimens for a single freeze-thaw cycle. The specimen is subjected to freezing at $-15 \pm 3{ }^{\circ} \mathrm{C}$ for a minimum duration of $16 \mathrm{~h}$ and then kept in hot water bath maintained at $60{ }^{\circ} \mathrm{C}$ for $24 \mathrm{~h}$. The specimens were tested for tensile strength as shown in Fig. 2. The ratio of ITS value of conditioned specimens to that of

Table 5 Volumetric and Marshall properties of SMA mixtures

\begin{tabular}{|c|c|c|c|c|c|c|c|c|c|c|}
\hline \multirow{3}{*}{$\begin{array}{l}\text { Mixture } \\
\text { Property }\end{array}$} & \multicolumn{5}{|c|}{ SMA 1} & \multicolumn{5}{|c|}{ SMA 2} \\
\hline & \multicolumn{5}{|c|}{ Bitumen content by weight of aggregate } & \multicolumn{5}{|c|}{ Bitumen content by weight of aggregate } \\
\hline & 5.0 & 5.5 & 6.0 & 6.5 & 7.0 & 5.0 & 5.5 & 6.0 & 6.5 & 7.0 \\
\hline$G_{\mathrm{MM}}\left(\mathrm{g} / \mathrm{cm}^{3}\right)$ & 2.498 & 2.48 & 2.463 & 2.446 & 2.43 & 2.483 & 2.466 & 2.449 & 2.432 & 2.416 \\
\hline$G_{\mathrm{MB}}\left(\mathrm{g} / \mathrm{cm}^{3}\right)$ & 2.34 & 2.359 & 2.369 & 2.361 & 2.363 & 2.332 & 2.342 & 2.345 & 2.348 & 2.343 \\
\hline VA $(\%)$ & 6.32 & 4.90 & 3.81 & 3.50 & 2.77 & 6.09 & 5.03 & 4.25 & 3.47 & 3.03 \\
\hline VMA $(\%)$ & 17.45 & 17.19 & 17.21 & 17.90 & 18.22 & 18.51 & 18.55 & 18.83 & 19.11 & 19.66 \\
\hline VFB (\%) & 62.28 & 69.96 & 76.45 & 79.12 & 83.46 & 67.10 & 72.91 & 77.45 & 81.83 & 84.57 \\
\hline $\mathrm{MS}(\mathrm{kN})$ & 14.64 & 17.66 & 20.1 & 19.17 & 17.83 & 14.58 & 15.69 & 19.35 & 18.83 & 15.06 \\
\hline $\mathrm{FV}(\mathrm{mm})$ & 3.05 & 3.60 & 4.10 & 4.15 & 4.55 & 3.15 & 3.35 & 3.50 & 3.60 & 3.75 \\
\hline MQ (kN/mm) & 4.80 & 4.90 & 4.90 & 4.62 & 3.92 & 4.63 & 4.68 & 5.53 & 5.23 & 4.02 \\
\hline $\mathrm{VCA}_{\mathrm{MIX}}$ & 39.40 & 39.23 & 39.28 & 39.82 & 40.08 & 38.18 & 38.24 & 38.49 & 38.73 & 39.18 \\
\hline $\mathrm{VCA}_{\mathrm{MIX}} / \mathrm{VCA}_{\mathrm{DRC}}$ & 0.923 & 0.919 & 0.92 & 0.933 & 0.939 & 0.878 & 0.880 & 0.885 & 0.891 & 0.901 \\
\hline OBC (\%) & 6.00 & & & & & 6.12 & & & & \\
\hline
\end{tabular}




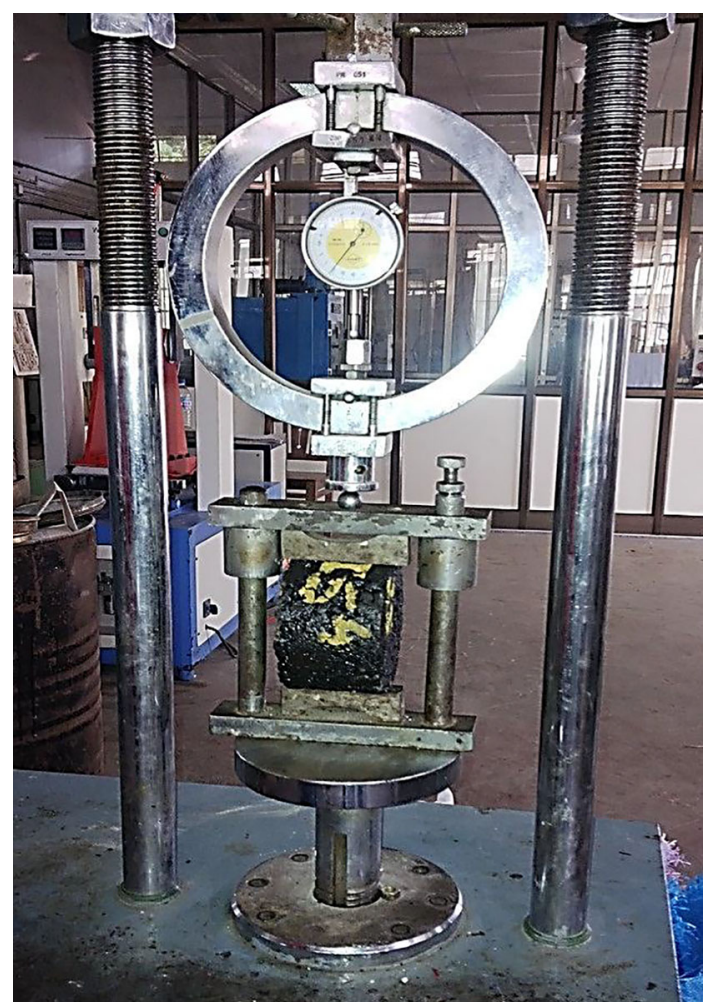

Fig. 2 ITS test setup

Table 7 ITS test results

\begin{tabular}{llll}
\hline SMA Mix & \multicolumn{2}{l}{ ITS $(\mathrm{MPa})$} & TSR $(\%)$ \\
\cline { 2 - 3 } & Unconditioned & Conditioned & \\
\hline SMA 1 & 1.110 & 1.013 & 91.26 \\
SMA 2 & 0.867 & 0.773 & 89.16 \\
\hline
\end{tabular}

normal specimens is known as tensile strength ratio (TSR), which is a measure of moisture resistance of bituminous mixtures. The results are presented in Table 7 and it can be seen that, ITS is better for SMA 1 mixtures for both conditioned and unconditioned cases and were having slightly higher TSR value compared to SMA 2 mixtures.

\subsection{Stripping}

Stripping or Boiling test is conducted to visually observe the stripping behaviour of mixture, which also gives an indication about the mixture's water sensitivity. In this study, loose SMA mixtures were tested for stripping as per both ASTM and Indian Standards (IS) methods. In ASTM method, the mixture is immersed in boiling water for 10 min, whereas in IS method, the mixture is kept in water bath at $60{ }^{\circ} \mathrm{C}$ for $24 \mathrm{~h}$. In both cases, stripping is determined by visual observation after the test duration. For

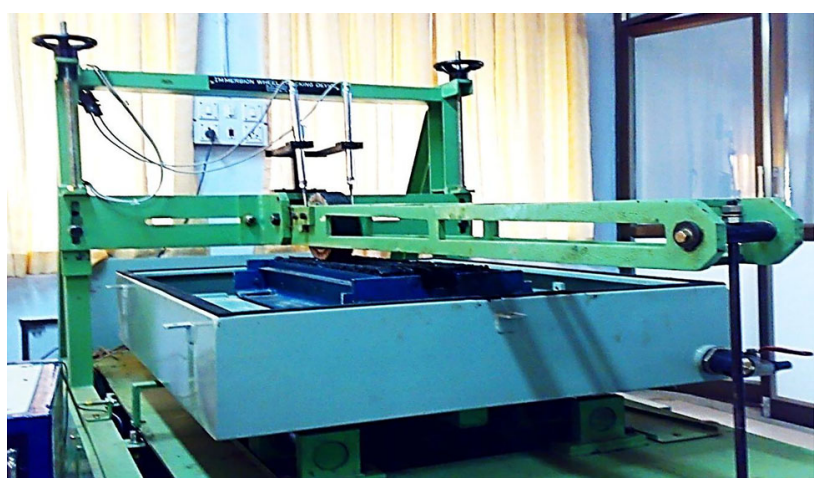

Fig. 3 Wheel-tracking device

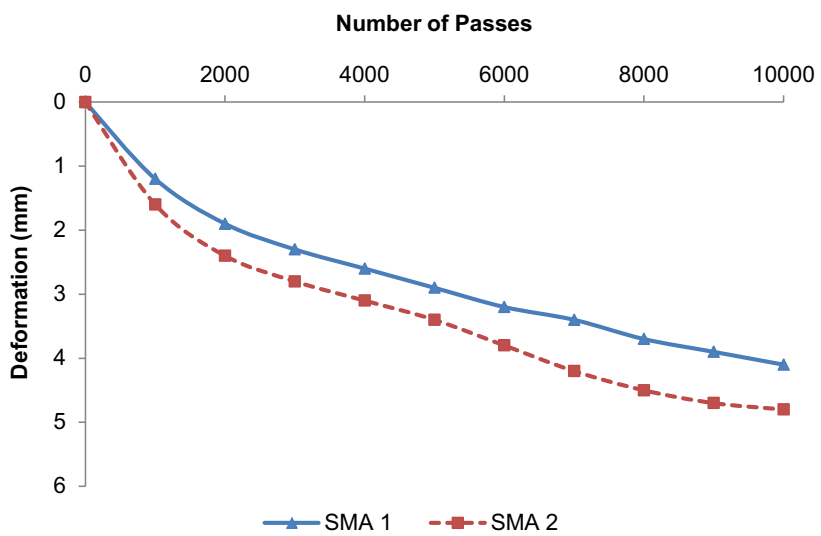

Fig. 4 Rutting test results for SMA mixtures

both SMA 1 and SMA 2 mixtures, very negligible stripping was observed.

\subsection{Rutting characteristics}

Rutting or permanent deformation is a major distress observed in flexible pavements. Rutting behaviour of SMA mixtures prepared in the study was assessed by wheeltracking test. The test was conducted using the wheeltracking device, shown in Fig. 3, on slabs with $600 \times 200 \times 50 \mathrm{~mm}$ size prepared at OBC for both SMA 1 and SMA 2 mixtures. The device has a loaded wheel and a confined steel mould in which the slab is rigidly restrained on all sides and placed on a platform. The wheel makes to and fro travel of $600 \mathrm{~mm}$ in the lengthwise direction along the middle of the slab. The deformation caused on the slab surface by this movement is recorded by means of two linear variable differential transducers (LVDTs) fixed on either side of the wheel and is displayed $[20,21]$.

The test was continued for 10,000 wheel passes and the final deformation was observed as 4.1 and $4.8 \mathrm{~mm}$ for SMA 1 and SMA 2, respectively. From the results depicted 


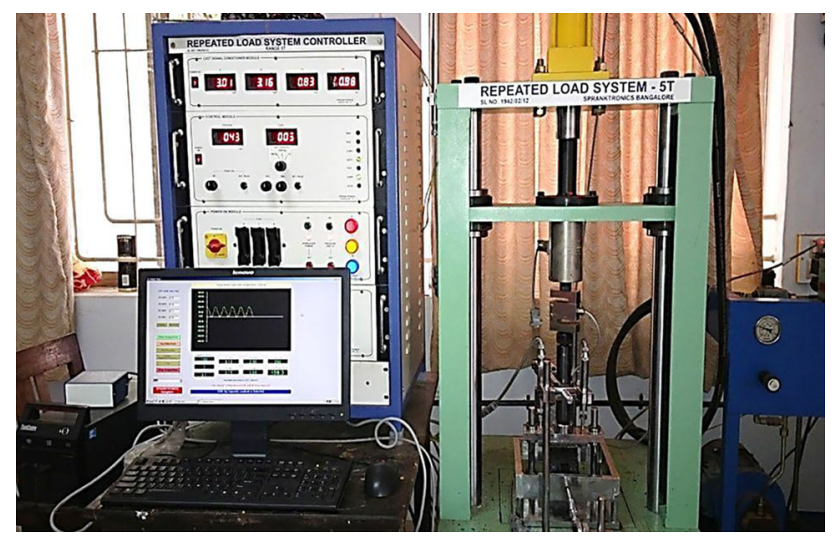

Fig. 5 Repeated load testing machine

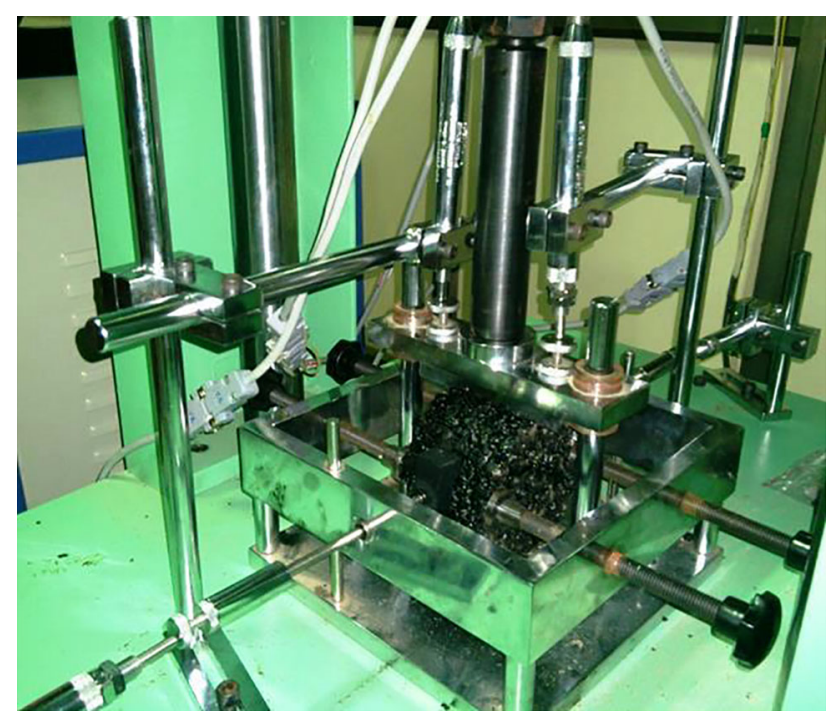

Fig. 6 Specimen arrangement in repeated load testing machine

in Fig. 4, it can be seen that SMA 2 slab was having slightly more rut depth at all wheel passes.

\subsection{Fatigue behaviour}

Behaviour of bituminous mixtures to repeated load application is a serious matter of concern. In this study, cylindrical SMA specimens were subjected to repeated dynamic loading in the repeated load testing machine, and the number of cycles required for the specimen to fail was considered as the fatigue life (FL). The machine, shown in Fig. 5, has a hydraulic loading system which applies dynamic load to the specimen, and a cooling system to control the temperature. The load is applied through a loading shaft, that can be moved in the vertical direction and the specimen is kept in a rigid rectangular frame below the shaft. The load is applied in positive half sine-wave pattern, with a loading frequency of $1 \mathrm{~Hz}$ and a rest period of $0.9 \mathrm{~s}$.
Table 8 Repeated load test results

\begin{tabular}{llll}
\hline Mix type & $\begin{array}{l}\text { Average load } \\
\text { applied }(\mathrm{kg})\end{array}$ & $\begin{array}{l}\text { \% of ITS } \\
\text { load }\end{array}$ & $\begin{array}{l}\text { Fatigue life } \\
\text { (No. of cycles) }\end{array}$ \\
\hline SMA 1 & 176.45 & 15.04 & 7562 \\
& 386.81 & 32.98 & 2993 \\
& 579.65 & 49.42 & 1269 \\
SMA 2 & 137.13 & 14.97 & 7256 \\
& 306.78 & 33.49 & 2645 \\
& 459.36 & 50.15 & 1093 \\
\hline
\end{tabular}

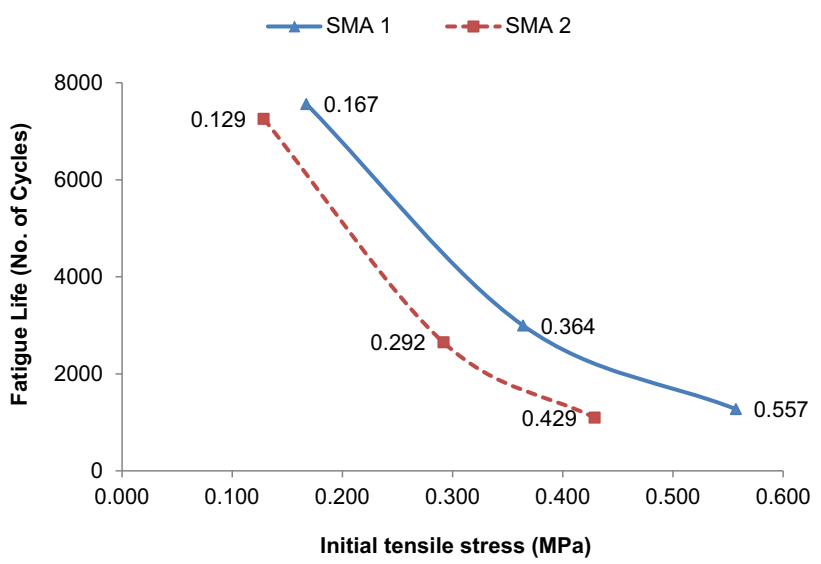

Fig. 7 Variation of fatigue life with initial tensile stress

Two horizontal and two vertical LVDTs (H1, H2, V1 and V2) are present in the set up to measure the deformation of specimen. The specimen arrangement is shown in Fig. 6. The machine is controlled and the data are recorded through a computer connected to it [22].

Specimens of SMA 1 and SMA 2, prepared at OBC, were subjected to approximately $15 \%, 33 \%$ and $50 \%$ of the corresponding ITS failure loads. Loading frequency was set as $1 \mathrm{~Hz}$, provided rest period of $0.9 \mathrm{~s}$ and the failure was considered at deflection of $5 \mathrm{~mm}$. From the results presented in Table 8 and Fig. 7, it can be observed that FL decreases with the increase in applied load and initial tensile stress $\left(\sigma_{i}\right)$. SMA 1 mixture performed better than SMA 2 in this test. Even though the applied load was more in the case of SMA 1, they withstood for more cycles. From the plot in Fig. 7, FL corresponding to constant $\sigma_{i}$ values for both mixtures can be calculated.

\section{Discussion and conclusion}

In this study, two aggregate gradations for SMA were adopted, SMA 1 and SMA 2, with NMAS 16 and 13.2, respectively. Same materials like, aggregate, bitumen and mineral filler were used and also same test conditions were maintained for 
both mixtures. The main difference between these gradations were in the NMAS and in the coarse aggregate sizes, but other important factors of gradation affecting the mixture performance were kept as uniform. The fraction of materials passing $4.75 \mathrm{~mm}$ sieve was $26 \%$ and $24 \%$, respectively for SMA 1 and SMA 2, and $75 \mu$ passing material was $10 \%$ for both mixtures. From the investigation, it can be seen that mixture with larger NMAS and more coarse aggregate sizes $(16,13.2$, 9.5 and $4.75 \mathrm{~mm}$ ) performs better than the other mixture, having coarse aggregate sizes 13.2, 9.5 and $4.75 \mathrm{~mm}$. SMA 1 mixtures showed higher density, stability and tensile strength, and were observed to be more rut resistant and having higher FL compared to SMA 2 mixtures. The improved performance of mixture with NMAS $16 \mathrm{~mm}$ may be attributed towards the presence of larger size coarse aggregates. For SMA 2, approximately $70 \%$ of the aggregates retain only on 9.5 and $4.75 \mathrm{~mm}$ sieves, whereas the same aggregate content is almost equally distributed among sieves $13.2,9.5$ and $4.75 \mathrm{~mm}$, in the case of SMA 1 mixture. The presence of more coarse aggregate sizes helps in attaining more density and strength for SMA 1 mixture.

From the laboratory investigation, following conclusions can be drawn.

- Both SMA mixtures satisfied drain down requirements without any stabilising additive and this is due to the usage of PMB as binder material.

- SMA 1 mixtures have comparatively higher density, stability and other volumetric and Marshall properties. OBC was found to be slightly less for these mixtures.

- For SMA 1 mixtures, tensile strength was $28 \%-31 \%$ higher than the other mix and moisture resistance was also slightly better.

- SMA 1 mixture was better resistant to rutting, and in wheel-tracking test, deformations were $0.4-0.7 \mathrm{~mm}$ less than SMA 2 slab for all wheel passes. After 10,000 passes rut depth was $4.1 \mathrm{~mm}$ for SMA 1, compared to $4.8 \mathrm{~mm}$ in the case of SMA 2 slab.

- At different proportions of ITS loads, fatigue life of SMA 1 mixes were about $10 \%$ higher than SMA 2, whereas at constant tensile stress, the improvement can be minimum $21 \%$.

Open Access This article is distributed under the terms of the Creative Commons Attribution License which permits any use, distribution, and reproduction in any medium, provided the original author(s) and the source are credited.

\section{References}

1. Brown ER, Haddock JE, Mallick RB, Lynn TA (1997) Development of a mixture design procedure for stone matrix asphalt
(SMA). Report No. 97-03, National Center for Asphalt Technology, Auburn University, Alabama, US

2. AASHTO (1990) Report on the 1990 European asphalt tour. AASHTO Report, Washington DC, US

3. Brown ER (1992) Evaluation of SMA used in Michigan (1991). Report No. 93-03, National Center for Asphalt Technology, Auburn University, Alabama, US

4. Qiu YF, Lum KM (2006) Design and performance of stone mastic asphalt. J Transp Eng 132(12):956-963. doi:10.1061/ (ASCE)0733-947X(2006)132:12(956)

5. Tashman L, Pearson B (2012) Characterisation of stone matrix asphalt mixtures. Int J Pavement Eng 13(4):297-309. doi:10. 1080/10298436.2011.595793

6. Brown ER, Bassett CE (1989) The effects of maximum aggregate size on properties of asphalt aggregate mixes. Report No. ER-8903, Highway Research Center, Auburn University, Alabama, US

7. Kim YR, Kim N, Khosla NP (1992) Effects of aggregate type and gradation on fatigue and permanent deformation of asphalt concrete. STP 1147: effects of aggregates and mineral fillers on asphalt mixture performance, ASTM, pp 310-328

8. Sridhar R, Kamaraj C, Bose S, Nanda PK, Singh M (2007) Effect of gradation and compactive effort on the properties of dense bituminous macadam mixes. J Sci Ind Res 66:56-59

9. Aodah HH, Kareem YNA, Chandra S (2012) Performance of bituminous mixes with different aggregate gradations and binders. Int J Eng Technol 2(11):1802-1812

10. Xie H, Cooley LA, Huner MH (2003) 4.75 mm NMAS stone matrix asphalt (SMA) mixtures. Report 03-05, National Center for Asphalt Technology, Auburn University, Alabama, US

11. Cooley LA, Hurley GC (2004) Potential of using stone matrix asphalt (SMA) in Mississippi. National Center for Asphalt Technology, Auburn University, Alabama

12. Brown ER (1992) Experience with stone matrix asphalt in the United States. Report 93-04, National Center for Asphalt Technology, Auburn University, Alabama, US

13. Prowell BD, Watson DE, Hurley GC, Brown ER (2009) Evaluation of stone matrix asphalt (SMA) for airfield pavements. Report No. AAPTP 04-04, Airfield Asphalt Pavement Technology Program, National Center for Asphalt Technology, Auburn University, Alabama, US

14. Scherocman JA (1991) Stone mastic asphalt reduces rutting. Better Roads 16(11):26-27

15. Brown ER, Mallick RB (1997) Evaluation of stone-on-stone contact in stone matrix asphalt. Transp Res Rec Transp Res Board 1583:95-102

16. Kandhal PS (2007) Specifications for stone matrix asphalt (SMA). Indian Highw Indian Roads Congr 35(2):37-48

17. Tentative Specifications for Stone Matrix Asphalt (2008) IRC SP 79. Indian Roads Congress, India

18. Brule B (1996) Polymer-modified asphalt cements used in the road construction industry: basic principles. Transp Res Rec Transp Res Board 1535:48-53

19. Technical Specifications for Construction of Highway Asphalt Pavements (2004) JTG F40-2004. Professional Standards of the People's Republic of China, Beijing

20. Ganesh K, Jagadeesh HS, Sathyamurty R (2010) Design of Automatic Immersion Wheel Tracking Equipment to measure the rutting characteristics of bituminous mixes with plain and modified binders. Highw Res J Indian Roads Congr 3(1):25-32

21. Shankar AUR, Koushik K, Sarang G (2013) Performance studies on bituminous concrete mixes using waste plastics. Highw Res J Indian Roads Congr 6(1):1-11

22. Sarang G, Lekha BM, Monisha M, Shankar AUR (2014) SMA mixtures with modified asphalt and treated aggregates. In: Proceedings of 2nd T\&DI congress, ASCE, Orlando, Florida, USA, pp 290-299 